\title{
Cost Utility of Splenic Artery Angioembolization for High-Grade Splenic Injury
}

\author{
HAMADA R. ABDELKADER, M.D.*; ABDELAZIZ A. ABDELHAFEZ, M.D.** and \\ AHMED M. ELBASIOUNY, M.D.*** \\ The Departments of General Surgery*, Vascular Surgery** and Radiology***, Faculty of Medicine, Al-Azhar University
}

\begin{abstract}
Background: Management of blunt spleen injuries has evolved from mandatory splenectomy to non-operative management (NOM) allowing for splenic salvage, Splenic artery embolization (SAE) has been shown to be an effective treatment for hemodynamically stable patients with high-grade blunt splenic injury. However, there are no local estimates of how much treatment costs.
\end{abstract}

Aim of Study: The aim of this study was to evaluate the cost of providing SAE to patients in the setting of blunt abdominal trauma with splenic injury and to determine if the costs of an added, preventative procedure (SAE) early in management of blunt splenic injury would be offset by added utility by avoiding splenectomy.

Patients and Methods: This study was a retrospective cohort study from a tertiary institution (50 patients in King Khaled Hospital Trauma Center, Hail, KSA and 9 patients in Al Hussein University Hospital, Cairo, Egypt). A total of 59 patients were treated with embolization in this period for blunt trauma, and however 39 cases were excluded given the presence of multiple concomitant injuries. Isolated splenic injury treated with SAE were identified in 20 patients and included for final analysis. Of these 10 patients, none required subsequent splenectomy following SAE.

Results: The mean total angiography costs were $1837.94 \pm$ $405.368 \$$, the costs of post-procedure management of patients including all hospital costs prior to discharge with associated length of stay.

Conclusion: Splenic embolization is a low-cost procedure for management of blunt splenic injury. The cost to provide $\mathrm{SAE}$ at our center was much lower than previously modelled data from overseas studies. Further research is advised to directly compare the cost of SAE and splenectomy in other countries.

Key Words: Splenic artery embolization - Blunt abdominal trauma - Non-operative management-Cost.

Correspondence to: Dr. Hamada R. Abdelkader, The Department of General Surgery, Faculty of Medicine, Al-Azhar University

\section{Introduction}

SPLEEN represents the most commonly damaged organ during abdominal blunt trauma and is affected in about one-third of patients with traumatic abdominal injuries [1].

Until the middle of the past century, early splenectomy represented the gold standard treatment for blunt splenic injuries. This operative approach was based on the concept that spleen does not play essential functions for life and consists of a highly vascularized parenchyma that may cause uncontrollable bleeding, if not surgically removed, even in case of minor lesions [2].

Embolization involves the use of an embolic material to either achieve hemostasis (distal embolization) or decrease pulse pressure and divert blood via collaterals (proximal embolization). Nonoperative management (NOM) with SAE has the benefits of preserving splenic function whilst avoiding complications of splenectomy. Another key advantage of SAE is the reduced length of hospital stay when compared to splenectomy. Use of SAE has been shown to have utility in patients with all grades of injury on the American Association for the Surgery of Trauma (AAST) splenic injury scale

The diagnosis of splenic injury following trauma is most frequently based on computed tomography (CT) scans. Numerous systems based on the extent of injury seen at CT, laparotomy or autopsy have been developed to grade traumatic splenic injuries

Splenic artery embolization (SAE) has been shown to be an effective treatment for haemodynamically stable patients with high-grade blunt 
splenic injury. However, there are no local estimates of how much treatment costs. Splenic injury commonly occurs following blunt abdominal trauma. In recent decades, the management paradigms for splenic injury in haemodynamically stable patients have shifted towards strategies aiming for splenic salvage, and splenic artery embolization (SAE) is an effective technique to achieve this, while some literature contends the universal adoption of SAE

The use of SAE for select high-risk patients undergoing non-operative management of splenic injury is widespread and supported by positive literature showing that it is a safe and efficacious procedure. Splenic embolization has also been shown to reduce the length of stay and hospital costs in comparison to surgical intervention. However, there is currently no data on the total costs of the procedure in the Australian healthcare system

The total cost of a procedure is a significant factor in its utilization, particularly in publiclyfunded healthcare networks. By characterizing the overall costs of a procedure, we can assess and improve its cost efficiency. However, there is no data on the cost of SAE in the Australian healthcare system [7]

With an increase in physician-direct cost containment, more and more economic evaluations of competing management strategies are occurring. Cost effective analyses are often employed when a randomized control trial cannot be completed. Randomizing patients to SAE or non-operative management (NOM) is not only cost prohibitive, but also impractical given the number of patients needed for adequate power. Currently there is no cost-utility analysis to assist surgeons in decisionmaking to add SAE to NOM of blunt spleen injury. The added costs of SAE may be offset by the added utility of avoiding an abdominal operation; nonetheless, complications are associated with SAE which may decrease the overall utility. Due to an escalation in the practice of routine SAE and conflicting failure rates in both NOM with SAE and NOM alone, we developed a cost-utility analysis to evaluate the accumulated costs associated with SAE added to NOM compared to NOM alone in patients with high grade blunt splenic injury [8].

The aim of our study was to evaluate the cost of providing SAE to patients in the setting of blunt abdominal trauma with splenic injury and to determine if the costs of an added, preventative procedure (SAE) early in management of blunt splenic injury would be offset by added utility by avoiding splenectomy.

\section{Patients and Methods}

This study was a single center retrospective cohort study from a tertiary institution.

\section{Inclusion criteria:}

- Patients who received SAE after abdominal trauma at our hospital from the 1-year period of December 1, 2018 to December 1, 2019 were included.

- Ages 16-99.

- All genders.

- Blunt trauma as the mechanism of injury.

\section{Exclusion criteria:}

Patients had other co-existent solid or hollow organ injury in the thoracic or abdominal cavity so as to exclude potential confounders of length of stay and treatment cost.

Patients were identified via retrospective search of the Radiology Information System (RIS) and Picture and Communications Archive (PACS) using an internal procedure code specifically linked to SAE. All patients who had received SAE were clearly identified and did not require use of a prospective hospital registry or cross-checking with discharge diagnosis codes.

\section{Costing:}

Procedure costs were calculated using a bottomup approach considering cost of equipment, staffing and machinery including servicing and depreciation. Data from the Victorian Cost Data Collection (VCDC) and Victorian Admitted Episodes Dataset (VAED) was retrieved from the blinded costing department for intensive care unit (ICU), ward, pharmacy, and other ancillary costs. VCDC data is calculated using a top down approach to allocate costs to all direct patient services included in an inpatient stay, as well as indirect costs associated with all hospital activity. In all cases, both direct and indirect costs were included.

\section{Statistical analysis:}

Anonymized costing data was analyzed using Microsoft Excel (Microsoft, USA) with the Real Statistics Resource Pack software (Release 6.8). Where relevant, data was summarized using mean and standard deviation (SD), median and range, or frequency and percentage as appropriate to the type of data. 


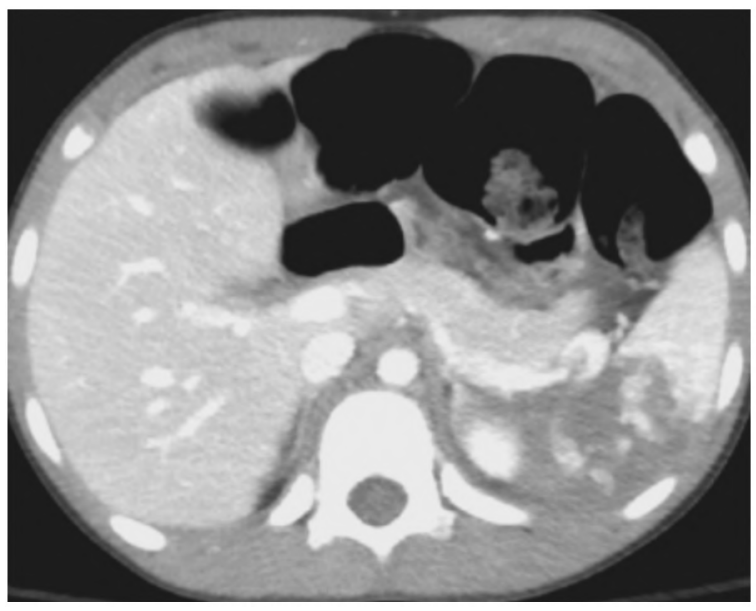

Fig. (1): CT Abdomen, post contrast study demonstrates splenic laceration with hilar vessels involvement.

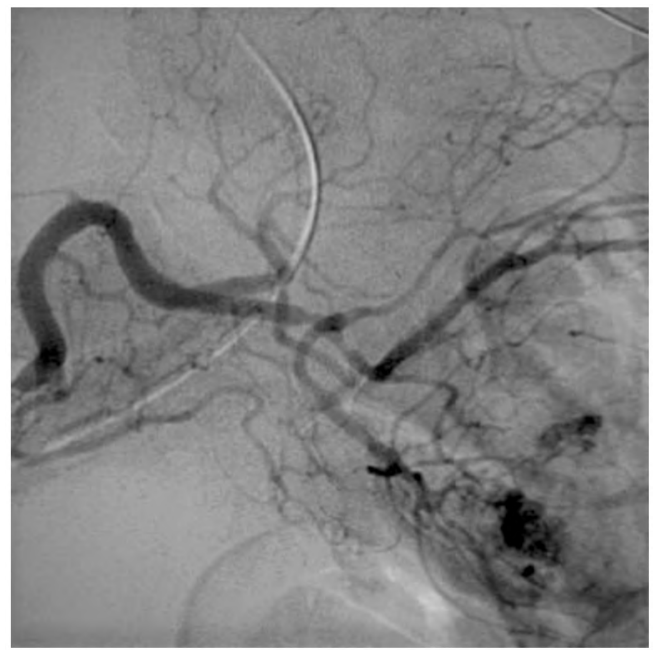

Fig. (3)

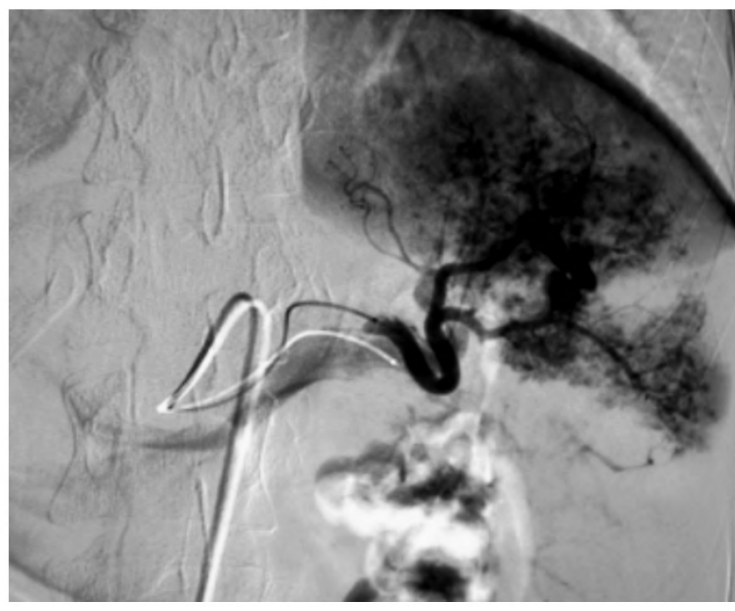

Fig. (2): Splenic angiogram shows heterogenous perfusion of the spleen with areas of poorly perfused parenchyma, as well early draining splenic vein impressive of traumatic arteriovenous fistula.

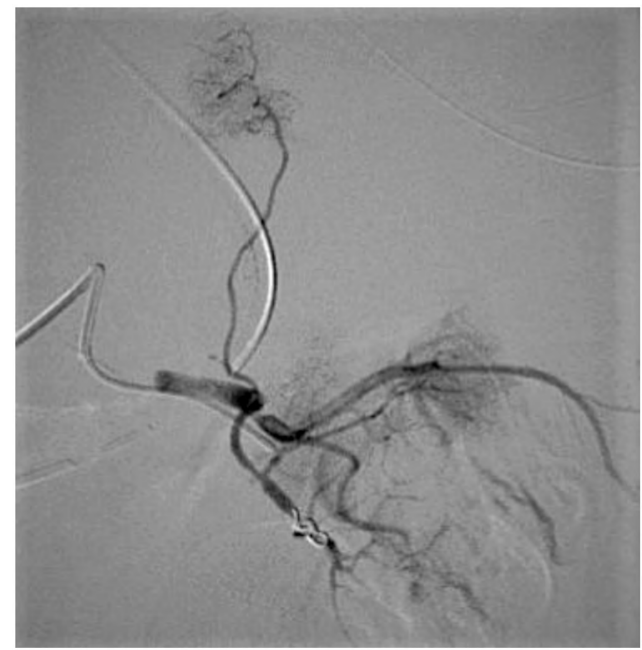

Fig. (4)

Fig. $(3,4)$ : Angiogram revealed distal curative embolization of post traumatic distal arterial bleeding using a microcatheter. before (3) and after coiling (4).

\section{Results}

A total of 59 patients were treated with embolization in this period for blunt trauma, however 39 cases were excluded given the presence of multiple concomitant injuries. Isolated splenic injury treated with SAE were identified in 20 patients and included for final analysis. Of these 10 patients, none required subsequent splenectomy following SAE.

Table (1) displays data regarding the age, gender, mechanism of injury, AAST splenic injury grade, Embolization location and length of stay of the patients. The mean age of patients was $39.70 \pm$ 18.882 years old at time of procedure, $70 \%$ were males, the most common mechanism was car accident (on road). The median grade of splenic injury according to the American Association for the Surgery of Trauma (AAST) was grade $4(60 \%)$. Of the 20 included cases, proximal coil embolization was performed in 15 , distal embolization in 4 , and tandem embolization (both proximal and distal). The mean procedure time was $72.40 \pm 13.551$ min. The mean ward length of stay was $4.10 \pm 0.968$ days. Seventeen patients were admitted to ICU following the procedure with a mean value of $1.45 \pm 0.999$. The mean total hospital stay was $5.55 \pm 1.099$ days.

Table (2) shows angiography costs and Post procedural ward costs. To calculate the angiography room costs, the procedure time was multiplied by an hourly rate which was calculated by including the wages of staff members in attendance ( 2 nurses, 1 radiographer and 1 interventional radiologist). 
This hourly rate included costs of running angiography equipment (including original cost of machine, depreciation, servicing and other running costs). The mean total angiography costs were $1837.94 \pm 405.368 \$$. the costs of post-procedure management of patients including all hospital costs prior to discharge with associated length of stay. Intensive care unit admission was employed in 17 patients. Other costs calculated included pharmacy, general ward costs (including overheads, ward costs, orderlies and ward nursing) and costs including allied health, imaging and pathology. The mean total cost of post procedural ward care was $7224.91 \pm 2590.354 \$$. the total cost per admission involving SAE. The mean total cost for admission was $9062.85 \pm 2496.444 \$$.

Table (1): Demographic and clinical data.

\begin{tabular}{ll}
\hline Age (years) & $39.70 \pm 18.882$ \\
Sex: & \\
Male & $14(70 \%)$ \\
Female & $6(30 \%)$ \\
Mechanism of injury: & \\
Car Accident & $9(45 \%)$ \\
Fall Down Stairs & $4(20 \%)$ \\
Fall from High & $6(30 \%)$ \\
Motorbike Accident & $1(5 \%)$ \\
AAST splenic injury grade: & \\
III & $7(35 \%)$ \\
IV & $12(60 \%)$ \\
V & $1(5 \%)$ \\
Embolization location: & \\
Proximal & $15(75 \%)$ \\
Distal & $4(20 \%)$ \\
Tandem & $1(5 \%)$ \\
Procedure time (mins) & $72.40 \pm 13.551$ \\
Ward Length of Stay (days) & $4.10 \pm 0.968$ \\
ICU Length of Stay (days) & $1.45 \pm 0.999$ \\
Total Hospital Stay (days) & $5.55 \pm 1.099$ \\
\hline
\end{tabular}

Table (2): Angiography costs and post procedural ward costs.

\begin{tabular}{ll}
\hline Angiography costs: & \\
Sheaths, equipment and closure (\$) & $854.30 \pm 201.273$ \\
Embolic agent (\$) & $516.61 \pm 392.853$ \\
Machine room, staff, total (\$) & $467.03 \pm 87.405$ \\
Total Angiography costs (\$) & $1837.94 \pm 405.368$ \\
Post procedural ward costs: & \\
Pharmacy Costs (\$) & $212.67 \pm 53.111$ \\
ICU Costs (\$) & $3263.25 \pm 2703.661$ \\
Ward costs (\$) & $3030.67 \pm 826.051$ \\
Other costs (allied health, imaging, & $718.32 \pm 314.681$ \\
$\quad$ pathology) (\$) & \\
Total Post procedural ward costs $(\$)$ & $7224.91 \pm 2590.354$ \\
\hline Total Costs & $9062.85 \pm 2496.444$ \\
\hline
\end{tabular}

\section{Discussion}

The use of SAE for select high-risk patients undergoing non-operative management of splenic injury is widespread and supported by positive literature showing that it is a safe and efficacious procedure. Splenic embolization has also been shown to reduce the length of stay and hospital costs in comparison to surgical intervention. However, there is currently no data on the total costs of the procedure in the Australian healthcare system [9].

In this study we aimed to evaluate the cost of providing SAE to patients in the setting of blunt abdominal trauma with splenic injury and to determine if the costs of an added, preventative procedure (SAE) early in management of blunt splenic injury would be offset by added utility by avoiding splenectomy.

We conducted the study on 20 patients diagnosed with isolated splenic injury treated with SAE, the mean age of patients was $39.70 \pm 18.882$ years old at time of procedure, $70 \%$ were males, the most common mechanism was car accident (on road). The median grade of splenic injury according to the American Association for the Surgery of Trauma (AAST) was grade $4(60 \%)$.

In agreement with our findings, the study of Yip et al., 2020 reported thatthe mean age of patients was 35.6 (SD 16.5) years old at time of procedure, $80 \%$ were males, the most common mechanism was bicycle accident (on road). The median grade of splenic injury according to the American Association for the Surgery of Trauma (AAST) was grade 4 (range 3-5) [10]

In another study Parihar et al., 2013 reported that group A consisted of 25 patients (21 male and 4 female, mean age 24.64 with range 5-60, mean ISS 19.2 with range 9-43, mean AAST grade 3.32 with range 2-5) with splenic injuries who were managed by SAE followed by non-operative management, and group B consisted of 20 patients (17 male and 3 female, mean age 24.95 with range 1345, mean ISS 14.9 with range 10-27, mean AAST grade 3 with range 3 ) who were treated by standard non-operative management, furthermore, the study (Teuben et al., 2020) reported that motorcycle accidents accounted for most injuries $(n=15)$. Falls from a height $(n=10)$ and falls from a bicycle $(n=7)$ were the second and third most frequent causes of blunt splenic injury respectively. Median (IQR) ISS was 16 (12-29), and 16 patients had an AIS splenic injury grade greater than 3 [12] 
Angiography with the option of performing splenic artery embolization has emerged as a viable option to decrease the rate of non-operative management failure. Embolization is completed either by occluding the main splenic artery, referred to as proximal embolization, or by selectively targeting splenic artery branches with visualized injuries on angiography, referred to as distal embolization. Proposed benefits to proximal embolization include speed and ease of procedure, lower cost, and fewer splenic abscesses and infarctions [13]. In the current study of the 20 included cases, proximal coil embolization was performed in 15, distal embolization in 4 , and tandem embolization (both proximal and distal). The mean procedure time was $72.40 \pm$ $13.551 \mathrm{~min}$. The mean ward length of stay was $4.10 \pm 0.968$ days. Seventeen patients were admitted to ICU following the procedure with a mean value of $1.45 \pm 0.999$. The mean total hospital stay was $5.55 \pm 1.099$ days.

Similar to our findings, the study Yip et al., 2020 reported that the median total length of stay in hospital was 4.5 days (range 4 to 7 days). Seven patients were admitted to ICU following the procedure with a median injury grade of 4 (range 3 to 5) for a median of 1 day (range 1 to 3 days). Of patients that were admitted to ICU they spent a median of 3 further days on the ward (range 2 to 5 days). For patients who were not observed in ICU, they had a median AAST injury grade of 4 (range 3 to 4 ) and were admitted to the ward for a median of 4 days (range 4 to 5 days) [10] .

Another study Parihar et al., 2013 was conducted ona total of 67 patients underwent non-operative management (NOM) for blunt splenic injuries. Twenty-two patients were excluded from the study because of associated significant other organ injuries. Twenty-five patients underwent SAE followed by NOM (group A) and 20 patients underwent standard NOM (group B), and reported that the mean length of ICU stay was lower in the group A patients (0.72 vs. 0.85-day, $p=0.797)$. The mean length of total hospital stay was also lower in the group A patients (5.4 vs. 6.6 days, $p=0.050$ ) [11].

Splenectomy continues to be the treatment of choice in patients with unstable hemodynamics and a known splenic injury. In the hemodynamically normal patient, current practice is to observe the patient and treat with NOM to save the patients the complications associated with surgery. There is a risk of failure of NOM, thus the addition of SAE as a prophylactic measure has been proposed to improve the rate of success of NOM. Currently it is unclear what benefit SAE adds as there is conflicting data regarding rate of failure comparing SAE to NOM. In addition, there is no clear guideline to determine which patient may benefit from the addition of SAE [14].

We developed this economic evaluation to assist clinical decision making when patients have high grade splenic injury, but who are hemodynamically normal, to calculate the angiography room costs, the procedure time was multiplied by an hourly rate which was calculated by including the wages of staff members in attendance ( 2 nurses, 1 radiographer and 1 interventional radiologist). This hourly rate included costs of running angiography equipment (including original cost of machine, depreciation, servicing and other running costs). The mean total angiography costs were $1837.94 \pm$ 405.368 \$. In Yip et al., 2020 study, they showed that the mean overall cost of SAE at study center was AUD \$10,523.70, which included all angiography suite costs and post-procedural ward costs including both direct and indirect costs where relevant [10].

Wahl et al., 2004 found the total cost for patients receiving SAE to be USD \$49,290 (AUD \$75,282) [15], whilst another study by Bruce et al., 2011 found the overall cost to be USD \$41,269 (AUD $\$ 63,031$ ) [7]. When comparing the costs of SAE versus surgical intervention, the study by Wahl et al., 2004 found minimal difference in the overall costs of patients receiving SAE and those receiving operative management, but postulated that this may be due to a bias leading to SAE patients routinely receiving post-procedure ICU monitoring [15].

In addition to above findings, the costs of postprocedure management of patients including all hospital costs prior to discharge with associated length of stay. Intensive care unit admission was employed in 17 patients. Other costs calculated included pharmacy, general ward costs (including overheads, ward costs, orderlies and ward nursing) and costs including allied health, imaging and pathology. The mean total cost of post procedural ward care was $7224.91 \pm 2590.354 \$$, the total cost per admission involving SAE. The mean total cost for admission was $9062.85 \pm 2496.444 \$$.

In agreement with our study, Yip et al., 2020 demonstrated that the costs of post-procedure management of patients including all hospital costs prior to discharge with associated length of stay. Intensive care unit admission was employed in 7 patients, whilst 3 patients were deemed to not require close observation. Other costs calculated 
included pharmacy, general ward costs (including overheads, ward costs, orderlies and ward nursing) and costs including allied health, imaging and pathology. The median total cost of post procedural ward care was AUD \$7596.2 (range \$3470.9 to $\$ 14,578.3)$ [10].

Senekjian et al., 2021 reported that the cost for an ICU stay was determined to be $\$ 2000 \pm \$ 919$ per day and $\$ 700 \pm \$ 283$ per day for an acute care bed. The mean length of ICU stay for patients undergoing splenectomy, SAE, and NOM was 5.7, 3.9 , and 4.0 days, respectively. The mean total hospital stay was $13.7,10.0$, and 11.0 days. The cost of each admission included one computed tomography (CT) scan which is \$8046/ \$258.27 Splenectomy and angiography each incurred a total cost of \$32,652 / \$5473 and \$15,976 / \$1017, respectively, as reported by AHRQ [8].

Finally, it would be ideal to have performed a direct cost comparison to purely conservative treatment (NOM without SAE) and additionally to splenectomy in a matched cohort of patients at our centre, conservative treatment of high-grade injuries including those with active bleeding or pseudoaneurysm at presentation is not practiced at our institution. In addition, splenectomy for an isolated splenic injury is extremely rare. For this reason, costs were compared to previously published overseas costs. A direct local cost comparison would be an ideal direction moving forward.

In conclusion, splenic artery embolization is an effective adjunct to NOM of splenic injury and we have shown that the cost to provide SAE at our centre was much lower than previously modeled data from previous studies.

Further research should be undertaken to compare the cost of SAE in a private versus public setting, and to compare the cost of SAE with splenectomy in an Egyptian setting at the same hospital and at the same time period. This information will be useful for government and health administration services to assist in allocation of health resources and provision of widespread interventional radiology services within trauma networks.

\section{References}

1- van der VLIES C.H., HOEKSTRA J., PONSEN K.J., REEKERS J.A., van DELDEN O.M. and GOSLINGS J.C.: Impact of splenic artery embolization on the success rate of nonoperative management for blunt splenic injury. Cardiovasc. Intervent Radiol., 35: 76-81, 2012.

2- CIROCCHI R., CORSI A., CASTELLANI E., BARBERINI F., RENZI C., CAGINI L., BOSELLI C. and
NOYA G.: Case series of non-operative management vs. operative management of splenic injury after blunt trauma. Ulus Travma Acil Cerrahi Derg., 20 (2): 91-6. doi: 10.5505/tjtes.2014.99442, 2014.

3- RONG J.J., LIU D., LIANG M., WANG Q.H., SUN J.Y., ZHANG Q.Y., et al.: The impacts of different embolization techniques on splenic artery embolization for blunt splenic injury: A systematic review and meta-analysis. Mil Med. Res., 4: 17, 2017.

4- RAIKHLIN A., BAERLOCHER M.O., ASCH M.R. and MYERS A.: Imaging and transcatheter arterial embolization for traumatic splenic injuries: Review of the literature. Canadian journal of surgery. Journal canadien de chirurgie, 51 (6): 464-472, 2008

5- PATIL M.S., GOODIN S.Z. and FINDEISS L.K.: Update: Splenic artery embolization in blunt abdominal trauma. Semin Intervent Radiol., 37 (1): 97-102, 2020.

6- AIOLFI A., INABA K., STRUMWASSER A., et al.: Splenic artery embolisation versus splenectomy: Analysis for early in-hospital infectious complications and outcomes. J. Trauma Acute Care Surg., 83 (3): 356-60, 2017.

7- BRUCE P.J., HELMER S.D., HARRISON P.B., et al.: Nonsurgical management of blunt splenic injury: Is it cost effective? Am. J. Surg., 202 (6): 810-15 discussion $5-6,2011$

8- SENEKJIAN L., CUSCHIERI J. and BRYCE R.H.: Robinson, Splenic artery angioembolization for high-grade splenic injury: Are we wasting money, The American Journal of Surgery 221: 204e210, 2021.

9- STASSEN N.A., BHULLAR I., CHENG J.D., et al.: Selective nonoperative management of blunt splenic injury: an Eastern Association for the Surgery of Trauma practice management guideline. J. Trauma Acute Care Surg., 73 (5 Suppl 4): S294-300, 2012.

10- YIP H., SKELLEY A., MORPHETT L., et al.: The cost to perform splenic artery embolisation following blunt trauma: Analysis from a level 1 Australian trauma centre, Injury, https://doi.org/10.1016/j.injury.2020.09.039.

11- PARIHAR M.L., KUMAR A., GAMANAGATTI S., BHALLA A.S., MISHRA B., KUMAR S., JANA M. and MISRA M.C.: Role of splenic artery embolization in management of traumatic splenic injuries: A prospective study. The Indian Journal of Surgery, 75 (5): 361-367. https://doi.org/10.1007/s12262-012-0505-9, 2013.

12- TEUBEN M., SPIJKERMAN R., TEUBER H., PFEIFER R., PAPE H.C., KRAMER W. and LEENEN L.: Splenic injury severity, not admission hemodynamics, predicts need for surgery in pediatric blunt splenic trauma. Patient safety in surgery, 14, 1. https://doi.org/10.1186/s13037019-0218-0, 2020.

13- CORN S., REYES J., HELMER S.D. and HAAN J.M.: Outcomes Following Blunt Traumatic Splenic Injury Treated with Conservative or Operative Management. Kansas Journal of Medicine, 12 (3): 83-88, 2019.

14- ROSENBERG G.M., WEISER T.G., MAGGIO P.M., et al.: The association between angioembolization and splenic salvage for isolated splenic injuries. J. Surg. Res., 229: 150e155, 2018.

15-WAHL W.L., AHRNS K.S., CHEN S., et al.: Blunt splenic injury: Operation versus angiographic embolisation. Surgery, 136 (4): 891-9, 2004. 


\section{هل من جدوى اقتصادية من الانصمام الو عائى للشريان الطحال

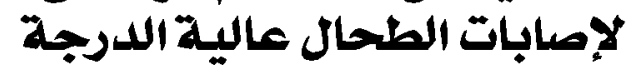

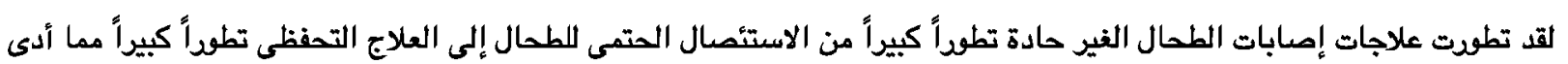

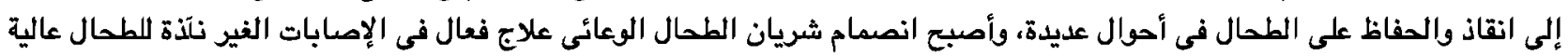

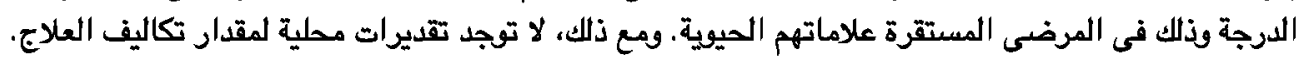

الهدف من هذه الدراسة: هو تقييم تكلفة الانصمام الوعائى اللشريان الطحالى فى علاج حالات الإصابات العالية الدرجة للطحال فى حالات

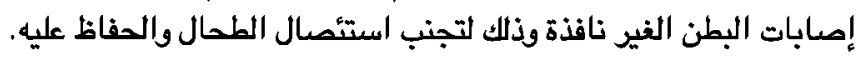

طريقة البحت: هذه الدراسة تمت بأثر رجعى على 9 هـ مريض من إصابات الحوادث ( (0 مريض بمستشفى الملك خالد بحائل، المملكة

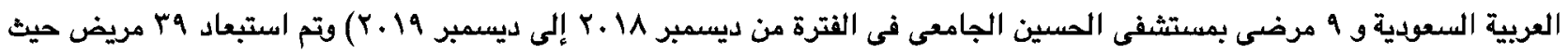

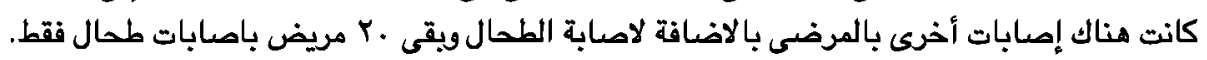

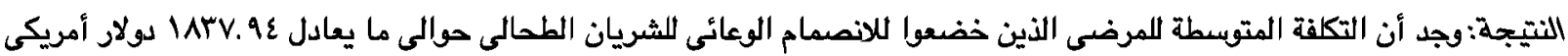

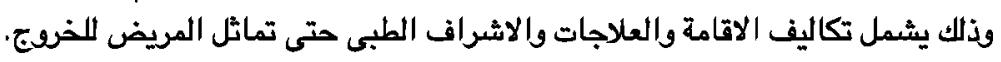

مما سبق تبين أن طريقة الانصمام الوعائى للشريان الطحالى فى علاج حالات اصابات الطحال عالية الدرجة هو اجراء منففض التكاليف

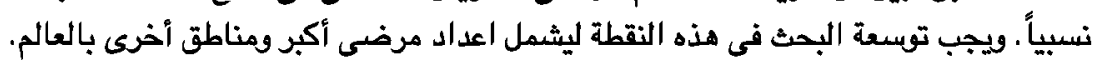

